\title{
ANÁLISES MULTIDIMENSIONAIS E O CONCEITO DO CUSTO PARA SERVIR EM EMPRESAS DE SERVIÇOS LOGÍSTICOS: UMA PESQUISA-AÇÃO
}

\section{MULTIDIMENSIONAL ANALYSIS AND THE CONCEPT OF COST TO SERVE IN COMPANIES OF LOGISTICS SERVICES: AN ACTION RESEARCH}

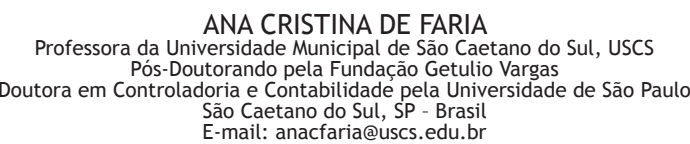

E-mail: anacfaria@uscs.edu.br

\section{MÁRCIO LUIZ BORINELLI
Professor da Universidade de São Paulo, USP, Brasil.
em Controladoria e Contabilidade pela Universidade de São Paulo. \\ MÁRCIO LUIZ BORINELLI
Professor da Universidade de São Paulo, USP, Brasil.
em Controladoria e Contabilidade pela Universidade de São Paulo. \\ MÁRCIO LUIZ BORINELLI
Professor da Universidade de São Paulo, USP, Brasil.
Doutorado em Controladoria e Contabilidade pela Universidade de São Paulo. São Paulo, SP - Brasil
E-mail: marciolb@usp.br}

NORIVAL MANTOVANI

Professor da Universidade Municipal de São Caetano do Sul, USCS, Brasil. Mestrado em Administração pela Universidade Municipal de São Caetano do Sul. São Caetano do Sul, SP - Brasil
E-mail: laviron@uol.com.br

\section{RESUMO}

O objetivo deste estudo é verificar, por meio de uma pesquisa-ação, as análises em nível multidimensional que podem ser desenvolvidas em uma empresa de serviços logísticos, visando a otimizar a tomada de decisões dos gestores, no que diz respeito aos objetos de análise filial, ponto de distribuição, rota e cliente. Para desenvolver a pesquisa-ação, buscou-se uma empresa prestadora de serviços logísticos com problemas de controle por falta de foco na gestão de custos; em que os sócios se envolvessem ativamente na pesquisa, de modo cooperativo e participativo. Foi constatado que as análises em nível multidimensional desenvolvidas contemplaram os resultados apurados nas operações incorridas nas filiais, rotas, pontos de distribuição e clientes. Diante dessas análises, foram identificadas as filiais, rotas e clientes mais rentáveis, otimizando suas decisões. A principal contribuição desta pesquisa está em servir de subsídio a outras organizações que necessitem analisar custos e resultados em uma perspectiva multidimensional.

Palavras-chave: Análise multidimensional; Custo para Servir; Lucratividade; Serviços logísticos.

\section{ABSTRACT}

The objective of this study is to verify, by means of action research, as analysis in multidimensional level in companies of logistics services can be developed to optimize decision making by management in respect analysis's objects subsidiary, distribution point, route and customer. To develop the action research a company of logistic services, with problems of control due to focus in the management of costs; where the partners to becoming involved themselves actively in the research, in cooperative and participative way. One evidenced that the developed analyses in multidimensional level, had contemplated the refined results in the operations incurred into the branch offices, routes, points of distribution and customers. From these analyses had identified which branch offices, routes and customers were most income-producing. The main contribution of this research is in serving of subsidy to other organizations that need to analyze costs and results in a multidimensional perspective.

Keywords: Cost to Serve; Logistic services; Multidimensional level; Profitability.

Enviado em:11/12/2009 - Aceito em: 13/08/2010 - 2a Revisão:11/09/2010

Aprovado no XVI Congresso Brasileiro de Custos - 2009 - Fortaleza/CE 


\section{INTRODUÇÃO}

Com o aumento da oferta de produtos/serviços, o mercado passou a determinar o preço a ser praticado pelas organizações e, nesse contexto, o gerenciamento adequado dos custos tornou-se uma vantagem competitiva relevante, independentemente do porte ou do segmento de atuação da empresa, na busca da otimização de seus resultados (MAXIMIANO, 2006).

Assim, o fato, muitas vezes, de os resultados econômico-financeiros ficarem cada vez mais reduzidos, obriga as empresas a buscarem meios de atrair novos clientes e conservar aqueles que oferecem resultados satisfatórios. Nesse contexto, além da preocupação em disponibilizar produtos/serviços de qualidade, as empresas devem buscar o atendimento ao cliente com a maior eficiência possível, preocupando-se com o nível de serviço a ser oferecido ao menor custo logístico total que se possa incorrer, que é o foco da logística integrada (JEFFERY; BUTLER; MALONE, 2008).

É fato que organizações de todo o mundo estão enfrentando desafios sem precedentes para a manutenção da lucratividade e rentabilidade, uma vez que os mercados em recessão aumentam a concorrência global, cada vez mais fortemente. É nesse cenário que a logística tem emergido como elemento vital no processo de renovação empresarial e sua contribuição pode cooperar para a consecução de vantagem competitiva sustentável; em particular, por meio do impacto combinado de uma melhoria do serviço prestado ao cliente (KUMAR; SHAH; VENKATESEN, 2006).

Nesse sentido, as empresas não podem mais somente manter a preocupação em aumentar as vendas, mas sim aumentá-las ou mantê-las com rentabilidade. Isto posto, para ser competitiva, uma empresa deve conhecer as suas fontes de lucro e compreender a sua estrutura de custos. Ademais, o atendimento às exigências dos clientes sempre teve um componente muito forte relacionado aos custos incorridos no atendimento a essas exigências, requerendo mecanismos de controle que permitam um claro entendimento das diversas variáveis que trazem algum tipo de dispêndio nas contas das empresas (KAPLAN e COOPER, 2000).

Por meio de observação empírica, assim como pela análise de diversos artigos publicados, é possível verificar que empresas de diferentes portes e segmentos buscam utilizar métodos sofisticados para apurar detalhadamente e mensurar os custos de produção/operação de seus produtos/serviços. Porém, muitas destas organizações ainda têm pouca noção do quanto representam os custos e resultados de outros objetos de análise, que não os produtos/serviços, tais como, rotas, canais de distribuição, filiais, clientes etc. Assumindo, por exemplo, que a filial, cliente ou canal de distribuição, também contribua para a geração do lucro, e não somente o produto/serviço, fica caracterizada, cada vez mais, a necessidade de identificação e mensuração dos custos do atendimento do nível de serviço exigido pelo cliente, uma vez que o custo do atendimento advém sempre do comportamento do cliente, em todas as fases do processo (GUERREIRO; BIO; MERSCHMANN, 2008).

O espectro total da visibilidade em tempo real e a gestão cada vez mais complexa e de alta velocidade nas operações será o marco de práticas de gestão logística e da cadeia de suprimentos neste século. Nesse escopo, uma questão importante da cadeia de suprimentos tem a ver com um plano de mudança e, simultaneamente, manter o foco na íntegra dos custos logísticos das empresas, utilizando um método 
conhecido como custo para servir (ROSS; JAYARAMAN; ROBINSON, 2007).

Assim, torna-se necessário à empresa identificar quais são os custos logísticos existentes em suas operações, visando a otimizar o resultado econômico-financeiro da empresa como um todo. Para tanto, é necessário que sejam analisados os custos logísticos associados aos diversos objetos, dependendo da análise que se pretende realizar. Torna-se, assim, essencial realizar apuração dos custos de todos os seus objetos de análise, tais como produtos ou serviços, canais de distribuição, regiões a serem atendidas, chegando ao nível da análise de rentabilidade do cliente que, Faria e Costa (2005) caracterizam como análises multidimensionais. Multidimensional, segundo Michaelis (2009), está associado a um espaço de mais de três dimensões. Neste estudo, a análise de lucratividade está sendo tratada como multidimensional, já que pode ser realizada para diversos objetos de análise, tais como produtos ou serviços, regiões ou filiais, clientes, canal de distribuição etc.

Em suma, considera-se que as mudanças verificadas nos últimos anos forçaram as empresas a reverem seus conceitos sobre as maneiras de gerir seus negócios, adotando-se uma visão mais integrada das diversas funções empresariais e, ao mesmo tempo, identificando a necessidade de visualização de todos os entes/objetos que, de alguma forma, influenciam os resultados das organizações. Diante da necessidade de analisarem-se os resultados multidimensionalmente, justifica-se a realização desta pesquisa. Até porque, a rentabilidade do cliente, por exemplo, é a chave para alinhar os incentivos entre as empresas e seus clientes (MITTAL; SARKEES; MURSHED, 2008).

Nesse contexto, ressalta-se que o Custeio Baseado em Atividades ( $A B C)$, relacionado com os objetos de custeio produtos, serviços, clientes, canais etc., proporciona às empresas uma informação mais clara, detalhada e precisa sobre as margens brutas e os custos para servir, quando os componentes de custos forem agregados à rentabilidade dos clientes (KAPLAN; NARAYANAN, 2001).

Portanto, estes pontos fundamentam os aspectos gerais da situação-problema a ser tratada durante este estudo, que consiste no fato de que a gestão de muitas empresas, em especial as de pequeno porte, desconhece quais são os custos e resultados auferidos em cada objeto de custeio existente. Considerando ser o assunto análise de resultados um tema bastante abrangente, e, tendo em vista a necessidade de olhar para isto por meio de uma perspectiva multidimensional, esse assunto será tratado em uma empresa de serviços logísticos de pequeno porte por meio da investigação da seguinte questão de pesquisa: Considerando-se uma abordagem multidimensional, quais análises podem ser desenvolvidas em uma empresa de serviços logísticos de pequeno porte, visando a otimizar a tomada de decisões dos gestores, no que diz respeito aos objetos de análise filial, ponto de distribuição, rota e cliente?

Para responder a esta questão, estabeleceu-se como objetivo geral deste estudo verificar, por meio de uma pesquisa-ação, as análises de lucratividade em nível multidimensional que podem ser desenvolvidas em uma empresa de serviços logísticos de pequeno porte, visando a otimizar a tomada de decisões dos gestores, no que diz respeito aos objetos de análise filial, ponto de distribuição, rota e cliente.

Em termos de contribuição, este estudo almeja contribuir com a empresa em estudo por meio do oferecimento de mecanismos (relatórios) de análise de 
lucratividade multidimensional que permitam à otimização das tomadas de decisão, no que diz respeito aos vários objetos de custeio existentes. Espera-se que o trabalho contribua com outras empresas no sentido de confirmar que é possível dispor de meios de análise de custos e resultados dos diversos objetos de custeios, que não apenas os produtos e serviços.

Assim, no intuito de responder à questão norteadora deste artigo, bem como atingir ao objetivo definido, além desta Introdução, o texto está organizado em mais cinco tópicos: a fundamentação teórica, em que será abordada a questão das análises multidimensionais e o conceito de custo para servir; os aspectos metodológicos, em que está explicitada a trajetória metodológica adotada no desenvolvimento deste trabalho; a pesquisa-ação no Grupo Oliveira, com foco na empresa IS que é operadora logística, que contempla a apresentação e análise dos resultados; as considerações finais sobre o assunto, bem como as referências que permeiam este artigo.

\section{FUNDAMENTAÇÃO TEÓRICA}

Ao longo dos anos, a margem de lucro tornou-se um tema muito preocupante, e muitos empresários foram pressionados a reduzi-la para manter seus clientes. Esses empresários tiveram que enfrentar um problema: ou voltar a aumentar os preços e correr o risco de perder o cliente para o concorrente, ou reduzir os custos para servir este cliente (MITTAL; SARKEES; MURSHED, 2008).

$\mathrm{Na}$ concepção de vários autores, como, por exemplo, Milone (2001), Faria e Costa (2005) e Guerreiro, Bio e Merschmann (2008), o custo para servir - Cost to Serve ${ }^{\circledR}$ pode ser definido como o método que visa a aperfeiçoar os sistemas que tratam da rentabilidade dos clientes com toda a profundidade requerida. Este conceito é decorrente do nível de serviço que a organização deseja estabelecer para atender aos seus clientes. Isto conduz ao fato de que o custo para servir contempla diversos objetos de custeio, haja vista que envolve diversos processos e atividades, como, por exemplo, transportar (rota), distribuir (ponto de distribuição), armazenar (centro de distribuição) etc. Assim, chegar à mensuração e gestão da lucratividade e rentabilidade de diversos objetos de análise é uma atividade que requer um bom suporte de tecnologia de informação; permitindo que a análise indique, com precisão e detalhe, os objetos que oferecem lucro e aqueles que não oferecem, ou seja, apenas geram margens que não cobrem totalmente os custos, em especial os custos para servi-los.

Nesse contexto, nem sempre o atendimento ao nível de serviço requerido pelo cliente mantém uma relação direta com o volume de vendas, de forma que clientes com volumes semelhantes não oferecem, necessariamente, a mesma rentabilidade. Assim, o nível de serviço poderá ser fixado, não somente em função dos anseios dos clientes, mas, também, em função da rentabilidade que oferecem à empresa (COKINS, 2006).

Assim, como discutem Faria e Costa (2005, p. 338), quando os custos do atendimento e as receitas são baixos, para determinados clientes, deveriam ser implantadas ações tentando aumentar o volume de vendas para esses mesmos clientes. De outra forma, se os custos são altos e as vendas têm um volume baixo, haveria 
a necessidade de uma avaliação na conveniência da manutenção desses clientes. Em outra situação, se os custos são altos e as vendas também, a gestão deve ser realizada no sentido de reduzir os custos e, no caso dos clientes com baixo custo e as vendas em um patamar elevado, poderiam ser desenvolvidos mecanismos para uma maior aproximação desses clientes, tentando criar um alto grau de fidelização. Essas diversas possibilidades podem ser visualizadas no Quadro 1, a seguir:

\begin{tabular}{|c|c|c|}
\hline Custos & Vendas & Ações \\
\hline Baixos & Baixas & Aumentar as vendas a esses clientes \\
\hline Altos & Baixas & Avaliar se vale a pena manter esses clientes \\
\hline Altos & Altas & Reduzir os custos com esses clientes \\
\hline Baixos & Altas & Fidelizar esses clientes \\
\hline
\end{tabular}

Quadro 1 - Ações requeridas nas relações entre os custos e os volumes associados aos Clientes

Fonte: Adaptado de Faria e Costa (2005, p. 338)

Nesse quadro de situações diferenciadas, cada uma exigindo ações que podem trazer alterações profundas no resultado econômico-financeiro das empresas, é muito mais interessante, e menos custoso, procurar manter e fidelizar os clientes mais rentáveis do que procurar novos clientes (FIGUEIREDO, 2000). A empresa objeto de pesquisa deste estudo, que será desenvolvido no tópico 4, encontra-se em uma situação deficitária, e diante disso, há necessidade de desenvolver um plano de ações para tentar focalizar esforços nas filias, rotas, pontos de distribuição e clientes mais lucrativos.

Em um estudo, Kumar, Shah e Venkatesen (2006) analisaram como pode ser computado a cada cliente o nível de serviço, visando a maximizar sua rentabilidade. O estudo mostrou que o máximo impacto positivo ocorre quando é feito o cruzamento do comportamento das compras do cliente com a sua maior permanência na empresa, comprando categorias específicas de produtos ou serviços.

Nessa linha de raciocínio, deve-se destacar que, os custos da logística de distribuição, que são o foco deste trabalho, podem variar de acordo com a localização dos clientes, embalagens, lotes de embarque e modais de transportes utilizados, assim como pela necessidade de centros de distribuição e sistemas de informações de apoio logístico. Dessa forma, pode ser considerada como essencial, uma gestão individualizada dos resultados econômicos por cliente/serviço, principalmente, pela intercorrência das atividades logísticas, as quais se evidenciam como essenciais na agregação de valor com níveis de serviços diferenciados, acoplados aos produtos e, muitas vezes, de forma personalizada a clientes específicos.

Kotler e Armstrong (2003) têm a opinião de que é melhor para a empresa ter um cliente satisfeito e fidelizado do que desenvolver novos clientes, uma vez que esta ação traz maiores custos para a empresa. Não obstante, esta decisão de escolha implica na mensuração de quais os clientes mais rentáveis, considerando não somente a rentabilidade, mas também a condição de fidelidade.

Figueiredo (2000) recomenda que, em vez de querer somente clientes satisfeitos, seja pensado em manter grupos de clientes mais satisfeitos, significando, 
assim, que clientes diferentes apresentam diversos níveis de rentabilidade para a empresa.

Howcroft (2005) afirma que, ao analisar a rentabilidade dos clientes, devese ter em mente que esta varia em função do custo para servir praticado para cada cliente, significando dizer que determinados pedidos são mais rentáveis do que outros, pois os custos incorridos para o atendimento de um pedido são, muitas vezes, bem diferentes do atendimento de outro pedido; muito embora os valores de ambos possam até ser iguais.

Norek e Pohlen (2001), por sua vez, esclarecem que vendas aos grandes varejistas, muitas vezes são feitas com prejuízo, ou seja, o custo ultrapassa a receita gerada pela venda, pois os fabricantes, frequentemente, não conhecem o custo para servir esses "grandes" clientes ou os custos das funções envolvidas nesse atendimento.

Toda a metodologia do custo para servir, de acordo com Braithwaite e Samakh (1998) e Norek e Pohlen (2001), está fundamentada nos conceitos do método do custeio baseado em atividades $(A B C)$, já que preconiza apropriar os recursos às atividades e, posteriormente, apropriar os custos destas atividades aos objetos de análise, tais como clientes, canais de distribuição etc.

Faria e Costa (2005) comentam que a diferença entre os métodos é muito sutil, pois a lógica do custo para servir é, praticamente idêntica à do $A B C$, sendo aplicada ao processo de logística de distribuição.

Assim, todo o entendimento do custo para servir está relacionado com a melhor adequação possível dos custos nos produtos ou serviços, nos canais de distribuição e nos clientes; porém, vai mais além, pois, para a obtenção dos resultados esperados, em especial o aumento de valor para os clientes e acionistas, haverá a necessidade de uma mudança na mentalidade da empresa que passará a focar sua gestão nos clientes e nos custos para servi-los.

Reeve (1998) afirma que o custo total da entrega, que pode ser associado ao custo para servir ao cliente, corresponde ao custo total de uma cadeia de valor, do fornecedor ao consumidor final, e que comparado à preferência de preço do cliente, alinha o custo da entrega e agrega valor para o cliente.

Este mesmo autor afirma que o método da análise de rentabilidade de relacionamento parte do princípio de que a combinação de atividades como vendas, logística e marketing permitem o conhecimento completo do custo para servir o cliente, assim como a possibilidade de analisar-se multidimensionalmente os resultados da empresa, tal como pode ser observado no Quadro 2, a seguir: 


\begin{tabular}{|c|c|}
\hline ITENS, CUSTOS E MARGENS & COMENTÁRIOS \\
\hline $\begin{array}{l}\text { Receita bruta para o item } \\
\text { (-) Descontos na lista de preços }\end{array}$ & $\begin{array}{l}\text { Lista de preços versus unidades vendidas pelo } \\
\text { sistema de pedidos de vendas; } \\
\text { Percentual da lista de preços (variações entre } \\
\text { cliente); } \\
\text { Percentual do preço de vendas depois dos } \\
\text { descontos deduzidos. }\end{array}$ \\
\hline (=) Receita líquida para a empresa & Atribuível para item da fatura. \\
\hline (-) Custos e despesas diretos variáveis do item faturado & $\begin{array}{l}\text { Os custos e despesas que podem ser atribuídos } \\
\text { para o nível de linhas dos itens faturados. }\end{array}$ \\
\hline \multicolumn{2}{|l|}{ (=) Margem de contribuição do item (produto/serviço) } \\
\hline $\begin{array}{l}\text { Somatório de todas as margens dos itens por } \\
\text { faturamento } \\
\text { (-) Custos e despesas diretos variáveis dos pedidos: } \\
\text {. desconto por tamanho de pedido } \\
\text {. embalagem/frete . recebimento do pedido }\end{array}$ & $\begin{array}{l}\text { Estes são custos diretos do pedido, mas comuns às } \\
\text { linhas de pedidos de venda dentro do pedido. }\end{array}$ \\
\hline \multicolumn{2}{|l|}{ (=) Margem de contribuição do pedido } \\
\hline $\begin{array}{l}\text { Somatório de todos os pedidos de um cliente } \\
\text { (-) Custos e despesas diretos variáveis do cliente: } \\
\text {. Propaganda } \\
\text {. Desconto comercial / Abatimento anual } \\
\text {. Serviços técnicos/Apoio em projetos } \\
\text { - Custo de manutenção do inventário } \\
\text {. Custo de manutenção de recebíveis }\end{array}$ & $\begin{array}{l}\text { Custos diretos para clientes, mas comuns para } \\
\text { produtos. Requerem registro da fatura e apoio pelo } \\
\text { código de cliente. } \\
\text { Custo do capital associado ao inventário requerido } \\
\text { para apoio ao cliente. } \\
\text { Custo do capital das duplicatas a receber dos } \\
\text { clientes. }\end{array}$ \\
\hline \multicolumn{2}{|l|}{ (=) Margem de contribuição do cliente } \\
\hline $\begin{array}{l}\text { Somatório de todas as margens dos clientes na região } \\
\text { (-) Custos e despesas diretos variáveis por região: } \\
\text {. Custos de arrendamento } \\
\text {. Salários de vendedores por região } \\
\text {. Custo de manter um cliente comum }\end{array}$ & $\begin{array}{l}\text { Custos variáveis diretos por região, mas comuns } \\
\text { aos clientes da região. } \\
\text { Custo de inventário não associado com nenhum } \\
\text { cliente, em particular. }\end{array}$ \\
\hline \multicolumn{2}{|l|}{ (=) Margem de contribuição da região / filial } \\
\hline $\begin{array}{l}\text { Somatório de todas as margens da região } \\
\text { (-) Custos comuns variáveis por região }\end{array}$ & $\begin{array}{l}\text { Estes são os custos remanescentes dos negócios } \\
\text { que são diretos para dimensões diferentes e } \\
\text { comuns às regiões. }\end{array}$ \\
\hline (=) Resultado Opera & \\
\hline
\end{tabular}

Quadro 2 - Composição da margem ao longo da dimensão dos objetos

Fonte: Adaptado de Reeve (1998) apud Faria e Costa (2005, p. 352)

O Quadro 2 evidenciou que Reeve (1998) desenvolveu uma estrutura teórica para atribuir os custos logísticos e mercadológicos aos diversos objetos de custeio, tais como: para a empresa como um todo; para o item (produto ou serviço); para o pedido; para o cliente e para a região ou filial; já que as receitas são facilmente identificadas aos diversos objetos, por meio do controle do faturamento. Essa visão é compartilhada por diversos autores, entre eles, Gattorna e Walters (1996) e Chistopher (2007), e pode ser aplicada a empresas dos mais diversos portes e segmentos.

A gestão dos custos relacionados com os diversos objetos supracitados no Quadro 2, seja no tocante aos aspectos da visão de marketing ou da logística, com o envolvimento dos gestores, conduz a uma postura estratégica de voltar a atenção 
para a análise de lucratividade e rentabilidade individualizada por cliente (STAPLETON et al., 2004). Tal postura cria uma necessidade de ter as ações de marketing e vendas dirigidas para o atendimento das exigências dos clientes, juntamente com a área operacional (envolvendo produção e logística), permitindo que as funções de Controladoria traduzam, por meio da perfeita gestão dos resultados econômicos, um tipo de informação muito refinado, tal como a análise da lucratividade e rentabilidade de cada cliente, traduzindo-se, ao final, em maior agregação de valor para os acionistas (ROBLES JR.; ROBLES; FARIA, 2005).

Nem sempre todos os custos são facilmente identificáveis a todos os objetos. Diante disso, alguns custos podem ser diretos a alguns objetos e indiretos a outros, requerendo análises mais aprofundadas para sua apropriação aos referidos objetos. A metodologia do Custo para Servir é uma derivação do Custeio Baseado em Atividades, que pode ser aplicada, com esse intuito aos demais objetos de análise, além de produtos e serviços. Na sequência, será apresentada a trajetória metodológica empregada nesta pesquisa.

\section{PROCEDIMENTOS METODOLÓGICOS}

Esta pesquisa empregou como estratégias a pesquisa bibliográfica e a pesquisaação. Recorre-se, inicialmente, à pesquisa bibliográfica no sentido de identificar os subsídios necessários para responder à questão norteadora e buscar o arcabouço para atender ao objetivo proposto. Ao buscar realizar a análise em nível multidimensional em uma pequena empresa de serviços logísticos, cujas características básicas atenderam ao foco da implementação do instrumento, visando a validá-lo em situação prática, a estratégia de pesquisa estudada e entendida como a mais adequada foi a pesquisa-ação.

Para Thiollent (2005, p. 14), a pesquisa-ação pode ser considerada como um instrumento de pesquisa científica; baseada empiricamente, concebida e realizada em associação com ação ou resolução de um problema coletivo, em que os pesquisadores e membros da situação estão envolvidos, cooperativa e participativamente. Riccio e Holanda (2001) comentam que a pesquisa-ação envolve uma equipe de profissionais e pesquisadores, que planejam, atuam e avaliam os resultados das ações realizadas, além de monitorar as atividades, por meio de diversos passos, até atingir resultados satisfatórios. Na opinião de Martins (2006, p. 47), esta metodologia associa a ação à pesquisa, em um processo em que os agentes envolvidos participam com o pesquisador, visando a elucidarem uma questão real em que estão inseridos; identificando problemas e testando soluções.

Quanto às demais classificações, esta pesquisa enquadra-se nas seguintes: descritiva quanto aos seus objetivos; aplicada ou empírica quanto à natureza do problema investigado; quantitativa quanto à abordagem do problema e natureza das variáveis pesquisadas; e de campo quanto ao ambiente de pesquisa (GIL, 2008).

$\mathrm{Na}$ visão de Stringer (1996 apud Krafta, 2007), este tipo de pesquisa compreende uma rotina que é composta por três ações básicas: observar, reunir informações e construir um cenário; refletir, explorar, analisar e interpretar os fatos; 
e posteriormente, agir, implantar e avaliar as ações. Thiollent (2005) considera que se pode dividir o processo de pesquisa-ação em quatro principais etapas que foram desenvolvidas neste estudo: fase exploratória, fase principal, fase de ação e fase de avaliação.

Para desenvolver a referida pesquisa, buscou-se uma pequena empresa administrada por sócios-proprietários, que, com foco na melhoria da gestão de seus custos e resultados econômicos, concordassem em envolver-se ativamente na pesquisa, de modo cooperativo e participativo, tal como preconiza a filosofia da pesquisa-ação. Com este foco em mente, identificou-se no município de São Paulo, considerado pólo de referência na atuação do ramo logístico, uma empresa de pequeno porte, cujas características de operação, comercialização, tributação e necessidades de novos métodos de gestão, adequaram-se à proposta de análise em nível multidimensional para melhoria na gestão desse pequeno negócio.

No contato inicial realizado com seus sócios-proprietários, realizado em maio de 2008, os mesmos demonstraram significativo interesse em ter acesso a novos instrumentos para a gestão de seu negócio, e entenderam ser a área de custos um dos pontos fundamentais a serem aprimorados em sua empresa. Diante disso, foi permitido aos pesquisadores o acesso a diversos dados de suas operações logísticas, que foram levantados e gerados por estes pesquisadores, em conjunto com a funcionária da área de custos da empresa. A pesquisa foi desenvolvida durante 180 dias, abrangendo parte do $2^{\circ}$. semestre de 2008 e os primeiros meses de 2009.

Assim, no intuito de verificar a aplicabilidade do sistema de custeio com abordagem multidimensional (vários objetos de custeio) na gestão dos micro e pequenos negócios, foi desenvolvida uma pesquisa-ação em uma pequena empresa do segmento de serviços logísticos.

\section{PESQUISA-AÇÃO EM EMPRESA DE SERVIÇOS LOGÍSTICOS DE PEQUENO PORTE}

\subsection{Apresentação da empresa e de seus processos logísticos}

Neste tópico será descrita a pesquisa-ação, que foi desenvolvida pelos pesquisadores em conjunto com os gestores da empresa.

O Grupo Oliveira é composto por três empresas societariamente distintas, e atua há sete anos no mercado, prestando serviços logísticos de distribuição de malotes corporativos para empresas de varejo. A operação realizada é semelhante à operação citada por Wang (2008). Estes malotes contêm, normalmente, documentos ou peças para trocas, que serão levados das lojas dos clientes para seus centros de distribuição e destes para as lojas. O grupo de empresas, foco deste estudo, será tratado a partir deste ponto como se fosse uma única entidade consolidada ou uma empresa denominada IS Logística (2010), para facilitar a descrição da pesquisa. Este grupo atua em oito Estados: SP, RJ, PR, MG, ES, BA, RS e DF. Em abril de 2009, apresentava um quadro de 45 funcionários e tinha um faturamento bruto médio mensal de R\$ 360 mil.

Nos últimos anos, o grupo passou por reestruturações organizacionais, em função da saída de alguns sócios da sociedade, atualmente em uma empresa concorrente. Atualmente, é dirigido por duas pessoas e composto por duas empresas 
societárias, ainda enquadradas no regime de tributação SIMPLES NACIONAL. O DiretorPresidente dedica-se à parte comercial e operacional, enquanto sua esposa à parte administrativa e financeira. Há outros gestores na área comercial, operacional e administrativa.

Os dirigentes do grupo mostraram-se bastante motivados com a possibilidade de desenvolver a pesquisa-ação, já que estavam em uma fase de transição com as supracitadas alterações societárias, e pretendiam implantar uma Controladoria na empresa. Inicialmente, os pesquisadores foram verificar quais os relatórios existentes, e depararam-se apenas com um fluxo de caixa elaborado em um sistema na internet. A empresa, no início da pesquisa, não possuía nenhum relatório de custos ou análises de lucratividade e rentabilidade, seja por tipo de serviço prestado, filiais, pontos ou clientes. A área comercial negociava um preço de mercado praticado pelos concorrentes com os clientes, mas não tinha noção se esse preço trazia rentabilidade positiva à empresa.

A IS opera com um Centro de Distribuição (CD) localizado no bairro do Cambuci, na cidade de São Paulo. Neste local, é feita toda a coordenação da operação da filial São Paulo, bem como se localizam as áreas comercial e administrativa. A coordenação é feita por uma supervisora e dois auxiliares. A coordenação operacional das outras filiais é feita por um ou dois funcionários, dependendo da complexidade da operação. O fluxo do processo operacional da IS pode ser visualizado na Figura 1, a seguir:

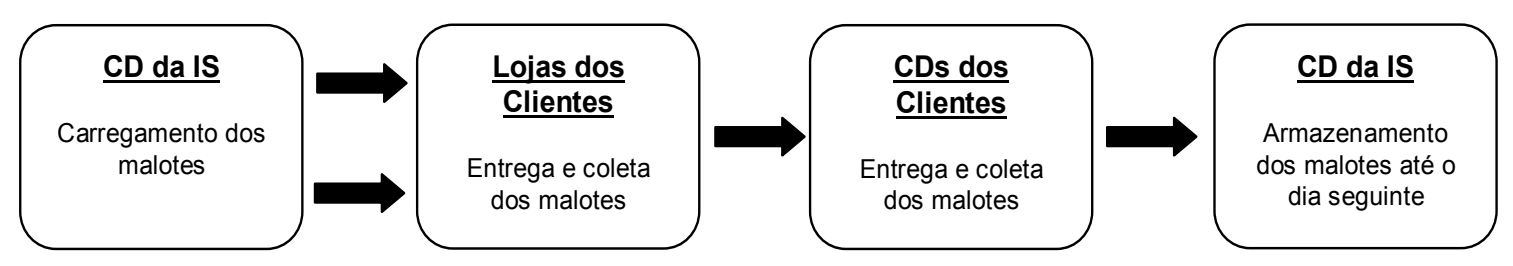

Figura 1 - Fluxo do processo operacional da IS

Fonte: Dados da Pesquisa (2009)

Mapeando o processo da operação logística realizada, percebeu-se que ocorrem as seguintes atividades: os motoristas dos veículos chegam ao CD da empresa, e das $8 \mathrm{~h}$ às $10 \mathrm{~h}$ carregam seus veículos ou motos com os malotes que serão distribuídos a partir das $10 \mathrm{~h}$ aos diversos pontos de entrega, em que estão localizadas as lojas dos clientes (empresas de varejo). Esses pontos podem localizar-se em ruas ou em shoppings centers. Nas lojas dos clientes são entregues os malotes e coletados os que as lojas querem que sejam levadas à sua central de distribuição. No final do dia, os motoristas levam os malotes coletados nas lojas às centrais dos clientes e pegam os que deverão ser entregues no dia seguinte. E aí, novamente o fluxo é iniciado.

\subsection{APRESENTAÇÃO E ANÁLISE DOS RESULTADOS}

A partir do mapeamento do processo logístico, os pesquisadores identificaram que os custos dos serviços prestados por esta empresa podem ser classificados em relação aos seguintes objetos de análise: empresa; filiais; veículos e rotas; pontos e clientes. Nesta pesquisa, não foi apurada a margem por pedido, ressaltada no Quadro 2 e as análises foram focalizadas nos objetos supracitados. 
Tabela 1 - Margem bruta por filial - IS (Em R\$)

\begin{tabular}{|c|c|c|c|c|c|c|c|c|c|}
\hline & & SP & R,J & DF & PR & MG & ES & BA & RS \\
\hline FATURAMENTO. BRUTO & 369.979 & 174.206 & 91.493 & 17.770 & 28.492 & 21.165 & 12.868 & 16.969 & 7.015 \\
\hline (-) Deduçōes de Vendas & -55.497 & -26.131 & -13.724 & -2.665 & -4.274 & -3.175 & -1.930 & -2.545 & -1.052 \\
\hline (=) FATURAMENTO LÍQUIDO & 314.482 & 148.075 & 77.769 & 15.104 & 24.218 & 17.990 & 10.938 & 14.423 & 5.963 \\
\hline (-) Custos Variáveis & -88.326 & -35.779 & -16.528 & -4.609 & -15.128 & -7.024 & -3.256 & -3.912 & -2.089 \\
\hline$(-)$ Comissōes $(3 \%)$ & -11.099 & -5.226 & -2.745 & -533 & -855 & -635 & -386 & -509 & -210 \\
\hline (=) MARGEM DE CONTRIBUIÇÃO (R\$) & 215.057 & 107.069 & 58.497 & 9.962 & 8.236 & 10.332 & 7.295 & 10.002 & 3.664 \\
\hline $\mathrm{MC}(\%)$ & 68,4 & 72,3 & 75,2 & 66 & 34 & 57,4 & 66,7 & 69,3 & 61,4 \\
\hline (-) Custos Fixos - Operação & -136.565 & 73.981 & 35.261 & 2.903 & 12.812 & 7.092 & 2.211 & 1.407 & 898 \\
\hline (=) MARGEM BRUTA (R\$) & 78.492 & 33.088 & 23.235 & 7.059 & -4.576 & 3.240 & 5.084 & 8.595 & 2.766 \\
\hline $\operatorname{MB}(\%)$ & 25 & 22,3 & 29,9 & 46,7 & $-18,9$ & 18 & 46,5 & 59,6 & 46,4 \\
\hline (-) Despesas Fixas & -50.971 & & & & & & & & \\
\hline (=) Res. Antes das Desp. Financeiras & 27.520 & & & & & & & & \\
\hline (-) Despesas Financeiras & -47.239 & & & & & & & & \\
\hline (=) RESULTADO OPERACIONAL & -19.719 & & & & & & & & \\
\hline
\end{tabular}

Fonte: Dados da Pesquisa (2009)

Observa-se que a margem de contribuição (MC) da empresa, de forma geral, é de $68,4 \%$ em relação ao faturamento líquido; e que as filiais de DF, PR, MG, ES e RS apresentam margens menores que esta média; sendo que a filial PR é a que requer mais atenção, já que evidencia uma MC de 34\%. As filiais de SP e RJ apresentam margens superiores à média geral, o que traria uma suposta tranquilidade aos gestores. Cabe ressaltar que neste trabalho optou-se por não apropriar as despesas fixas (administrativas e comerciais) e as despesas financeiras para as filiais, tratandoas como corporativas, para não entrar na discussão de qual o melhor direcionador de custos a ser utilizado para tal.

Quando se analisam as margens brutas (MB), em que são apropriados os custos fixos específicos de cada filial, a situação fica um pouco mais crítica. A MB média da empresa é de $25,0 \%$ em relação ao faturamento líquido, e as filiais SP e MG apresentam margens menores que essa; sendo que a filial PR já apresenta uma margem negativa de 18,9\%. A área comercial justificou que, ainda está prospectando novos clientes para cobrir os custos desta filial, e a área operacional está estudando maneiras de reduzir os custos dessa operação.

Que outro tipo de análise pode ser utilizada para que o gestor possa otimizar suas decisões? Então, surge uma questão: será que todas as rotas, pontos de distribuição e clientes são lucrativos? 0 gestor precisa de uma resposta para essa pergunta, já que se observa na Tabela 1 que a empresa como um todo apresenta prejuízo em suas operações, em função de altas despesas fixas (administrativas e comerciais) e dos problemas financeiros que está vivendo; e há necessidade de reverter essa situação, visando a manter a continuidade do negócio.

Como toda a negociação com os clientes é feita por pontos de distribuição atendidos, considerando a distância entre a central de distribuição do cliente, as lojas e a base de operação do operador logístico, a segunda análise a ser feita, que não requer muita dificuldade é a da apuração da $M B$ por ponto atendido em cada filial, que será evidenciada na Tabela 2, a seguir: 
Tabela 2 - Margem bruta por ponto atendido em cada filial - IS (Em R\$)

\begin{tabular}{c|c|c|c|c|c|c|c|c|c}
\hline & Total & SP & RJ & DF & PR & MG & ES & BA & RS \\
\hline (=) Margem Bruta & 78.492 & 33.088 & 23.235 & 7.059 & $(4.576)$ & 3.240 & 5.084 & 8.595 & 2.766 \\
\hline ?MB (\%) & $25 \%$ & $22,3 \%$ & $29,9 \%$ & $46,7 \%$ & $-18,9 \%$ & $18,0 \%$ & $46,5 \%$ & $59,6 \%$ & $46,4 \%$ \\
\hline $\begin{array}{c}\text { Pontos de } \\
\text { Distribuição }\end{array}$ & 1.874 & 1.234 & 378 & 37 & 117 & 62 & 22 & 16 & 8 \\
\hline $\begin{array}{c}\text { Margem Bruta por } \\
\text { ponto de distribuição } \\
\text { (R\$) }\end{array}$ & 42 & 27 & 61 & 191 & $(39)$ & 52 & 231 & 537 & 346 \\
\hline
\end{tabular}

Fonte: Dados da Pesquisa (2009)

Como se pode observar, a MB média por ponto atendido é de $\mathrm{R} \$ 42$. Dessa maneira, constata-se que as operações de DF, ES, BA e RS são bastante lucrativas, seguidas por RJ e MG, e deveriam ser potencializadas, pois contribuem para otimizar o resultado da empresa. Por outro lado, a operação de PR apresenta resultado negativo, o que denota a necessidade de uma análise aprofundada de sua operação. Os gestores da empresa estão estudando ações para reduzir os custos da operação paranaense, optando por atuar com transportadoras em algumas rotas, em vez de ter operação própria. Da mesma forma, a operação de São Paulo, que apresenta margem menor que a média geral da empresa, precisa ser mais bem analisada.

Diante disso, optou-se por analisar os custos variáveis e fixos da rotas de distribuição. A gestora operacional optou por iniciar o trabalho pela filial São Paulo, que possui 15 diferentes rotas, e está sob sua gestão direta, facilitando a acessibilidade das informações, mesmo que o correto, tecnicamente, seria iniciar pela filial PR que apresenta lucratividade negativa. Para isso, foi necessário saber quais as rotas existentes na filial São Paulo e se existiam veículos específicos para cada rota, visando a facilitar a apuração dos custos diretos de cada rota, e posteriormente de cada ponto de distribuição e cliente.

As 15 rotas existentes na Filial São Paulo são: Centro, Centro 1, Norte, Sul, Sul 1, Leste, Grande ABC, Oeste, Osasco, Grande ABC, Litoral Sul, Sorocaba, Campinas, Vale do Paraíba e Ribeirão Preto. No início dos trabalhos, houve dificuldade para apuração dos custos por rota, já que os motoristas e ajudantes não tinham rotas fixas, além de que cada um abastecia nos postos em que achava melhor, apenas trazendo as notas fiscais para reembolso, o que dificultava o trabalho de apuração dos custos.

Os pesquisadores sugeriram que fossem fixados um motorista e um ajudante para cada carro, e que cada carro faria uma rota; inclusive para melhorar o controle dos custos variáveis por carro e por rota. Após terem sido desenvolvidos e implementados alguns controles semanais de quilometragem rodada e custos variáveis por carro (combustíveis, pedágios, estacionamentos, lavagens etc., tornouse possível a apuração dos custos por veículo e rota. A apuração desses custos pode ser visualizada na Tabela 3, a seguir: 
Tabela 3 - Custos Diretos Mensais das Rotas Paulistas (Em R\$)

\begin{tabular}{|c|c|c|c|c|c|c|c|c|c|c|c|c|}
\hline \multirow[b]{2}{*}{ 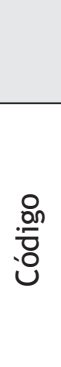 } & \multirow[b]{2}{*}{ 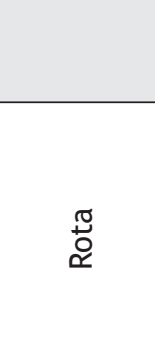 } & \multicolumn{2}{|c|}{$\begin{array}{c}\text { Custos } \\
\text { Operação }\end{array}$} & \multicolumn{5}{|c|}{ Custos Combustíveis } & \multicolumn{3}{|c|}{ Custos - Frota } & \multirow{2}{*}{$\begin{array}{c}\begin{array}{c}\text { Custos } \\
\text { Diretos }\end{array} \\
\text { Total }\end{array}$} \\
\hline & & $\begin{array}{l}\frac{0}{0} \\
\frac{0}{0} \\
\frac{0}{0} \\
0\end{array}$ & 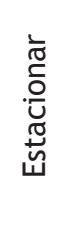 & $\begin{array}{l}\text { 음 } \\
\frac{7}{0} \\
\frac{0}{} \\
\text { हุ }\end{array}$ & 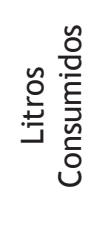 & 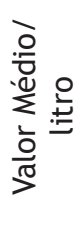 & 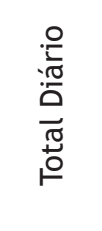 & 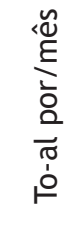 & 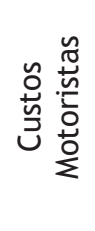 & 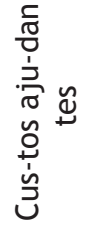 & 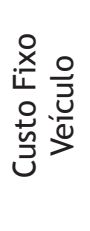 & \\
\hline 1 & Centro & 0 & 79 & 45 & 5 & 1,70 & 8,50 & 187 & 1631 & 1261 & 759 & 3.838 \\
\hline 2 & Centro 1 & 0 & 154 & 60 & 6,67 & 1,70 & 11,33 & 249 & 1631 & & 765 & 2.645 \\
\hline 3 & Norte & 0 & 0 & 74 & 8,22 & 1,70 & 13,97 & 307 & 1631 & 1261 & 759 & 3.959 \\
\hline 4 & Sul & 0 & 154 & 79 & 8,78 & 1,70 & 14,91 & 328 & 1631 & 1261 & 759 & 3.979 \\
\hline 5 & Sul 1 & 0 & 96 & 95 & 10,56 & 1,70 & 17,93 & 395 & 1631 & & 765 & 2.790 \\
\hline 6 & Leste & 0 & 0 & 99 & 11,00 & 1,70 & 18,69 & 411 & 1631 & 1261 & 765 & 4.068 \\
\hline 7 & $\begin{array}{l}\text { Grande } \\
\text { SP }\end{array}$ & 211 & 0 & 181 & 20,11 & 1,70 & 34,17 & 752 & 1631 & & 765 & 3.148 \\
\hline 8 & Oeste & 139 & 0 & 155 & 17,22 & 1,70 & 29,26 & 644 & 1631 & & 765 & 3.040 \\
\hline 9 & Osasco & 165 & 40 & 130 & 14,44 & 1,70 & 24,54 & 540 & 1631 & & 765 & 2.936 \\
\hline 10 & $\begin{array}{c}\text { Grande } \\
\text { ABC }\end{array}$ & 0 & 88 & 102 & 11,33 & 1,70 & 19,26 & 424 & 1631 & 1261 & 765 & 4.081 \\
\hline 11 & $\begin{array}{l}\text { Litoral } \\
\text { Sul }\end{array}$ & 539 & 0 & 218 & 24,22 & 1,70 & 41,15 & 905 & 1631 & & 765 & 3.301 \\
\hline 12 & Sorocaba & 777 & 7 & 371 & 41,22 & 1,70 & 70,04 & 1541 & 1631 & & 765 & 3.937 \\
\hline 13 & Campinas & 337 & 0 & 417 & 46,33 & 1,70 & 78,72 & 1732 & 1631 & & 765 & 4.128 \\
\hline 14 & $\begin{array}{c}\text { Vale } \\
\text { Paraíba }\end{array}$ & 737 & 0 & 487 & 54,11 & 1,70 & 91,93 & 2023 & 1631 & & 765 & 4.418 \\
\hline 15 & $\begin{array}{l}\text { Ribeirão } \\
\text { Preto }\end{array}$ & 1.804 & 0 & 883 & 98,11 & 1,70 & 166,7 & 3667 & 1631 & & 765 & 6.063 \\
\hline
\end{tabular}

Fonte: Dados da Pesquisa (2009)

Foram identificados os custos diretos das rotas paulistas, incluindo os fixos (motorista, ajudante, leasing, seguros etc.) e os custos variáveis. Não basta analisar os valores absolutos dos custos diretos, pois apenas seriam identificadas as rotas com maiores custos. Um indicador interessante de ser analisado seria o "custo direto da rota por pontos ou clientes atendidos".

Foi-se, então, apurada essa informação, conforme demonstra a Tabela 4: 
Tabela 4 - Custos Diretos Médios por Ponto Atendido nas Rotas Paulistas (Em R\$)

\begin{tabular}{|c|c|c|c|c|c|}
\hline & ROTA & $\begin{array}{l}\text { CUSTOS } \\
\text { DIRETOS DA } \\
\text { ROTA }\end{array}$ & $\begin{array}{c}\text { PONTOS } \\
\text { ATENDIDOS POR } \\
\text { ROTA }\end{array}$ & $\begin{array}{c}\text { \% DE PONTOS } \\
\text { ATENDIDOS POR ROTA }\end{array}$ & $\begin{array}{l}\text { CUSTO POR PONTO } \\
\text { ATENDIDO }\end{array}$ \\
\hline 1 & CENTRO & 3.838 & 88 & $9 \%$ & 43,62 \\
\hline 2 & CENTRO 1 & 2.645 & 22 & $2 \%$ & 120,23 \\
\hline 3 & NORTE & 3.959 & 94 & $10 \%$ & 42,11 \\
\hline 4 & SUL & 3.979 & 113 & $12 \%$ & 35,22 \\
\hline 5 & SUL 1 & 2.790 & 48 & $5 \%$ & 58,13 \\
\hline 6 & LESTE & 4.068 & 72 & $8 \%$ & 56,50 \\
\hline 7 & GRANDE SP & 3.148 & 47 & $5 \%$ & 66,97 \\
\hline 8 & OESTE & 3.040 & 86 & $9 \%$ & 35,34 \\
\hline 9 & OSASCO & 2.936 & 25 & $3 \%$ & 117,43 \\
\hline 10 & GRANDE ABC & 4.081 & 68 & $7 \%$ & 60,01 \\
\hline 11 & LITORAL SUL & 3.301 & 31 & $3 \%$ & 106,49 \\
\hline 12 & SOROCABA & 3.937 & 64 & $7 \%$ & 61,51 \\
\hline 13 & CAMPINAS & 4.128 & 94 & $10 \%$ & 43,91 \\
\hline 14 & VALE PARAÍBA & 4.418 & 38 & $4 \%$ & 116,28 \\
\hline \multirow[t]{2}{*}{15} & $\begin{array}{c}\text { RIBEIRÃO } \\
\text { PRETO } \\
\end{array}$ & 6.063 & 68 & $6 \%$ & 89,16 \\
\hline & TOTAL & 56.331 & 958 & & 58,80 \\
\hline
\end{tabular}

Fonte: Dados da Pesquisa (2009)

Analisando-se a informação evidenciada pela Tabela 4, observa-se que o custo direto médio da filial SP é de $\mathrm{R} \$ 58,80$. A rota que mais tem pontos atendidos diariamente (113) é a Sul que apresenta o menor custo direto médio $(R \$ 35,22)$, enquanto a rota que atende menos pontos diariamente, Centro 1, (22), é a que apresenta o maior custo direto médio ( $R \$ 120,23)$. Isso denota que as rotas que apresentam custos diretos médios superiores à média da filial, tais como, Centro 1, Grande SP, Osasco, Grande ABC, Litoral Sul, Sorocaba, Vale do Paraíba e Ribeirão Preto precisam ser reavaliadas pelas áreas comercial e operacional da empresa de logística de distribuição de malotes. Observa-se, inclusive, que, no geral, quanto maior o número de pontos atendidos, menor é custo por ponto.

A próxima análise a ser desenvolvida é a do Custo para Servir a cada cliente em cada rota e em cada ponto, numa visão multidimensional. No entanto, essa informação encontrava-se indisponível até o fechamento deste trabalho, pois a área de Contas a Receber do grupo tem controles de faturamento por cliente, sem a segregação por filial, rotas ou pontos. Diante desse cenário, buscou-se apurar a margem bruta por cliente, considerando como direcionador de resultados o montante de faturamento em reais de cada cliente, conforme evidencia a Tabela 5. em que estão sendo apresentados apenas os resultados por clientes da filial SP: 
Tabela 5 - Faturamento e Margem operacional por cliente da filial SP (Em R\$)

\begin{tabular}{|c|c|c|c|c|c|c|c|c|c|}
\hline \multicolumn{2}{|c|}{ Faturamento } & \multirow{2}{*}{$\begin{array}{c}\text { Bruto } \\
0 \% \\
\end{array}$} & \multirow[b]{2}{*}{31} & \multirow[b]{2}{*}{2.481} & \multirow[b]{2}{*}{$1 \%$} & \multicolumn{3}{|c|}{ Margem Operacional } & \multirow[b]{2}{*}{471} \\
\hline 1 & 330 & & & & & 1 & 63 & 31 & \\
\hline 2 & 3.176 & $2 \%$ & 32 & 7.026 & $4 \%$ & 2 & 603 & 32 & 1.334 \\
\hline 3 & 2.969 & $2 \%$ & 33 & 502 & $0 \%$ & 3 & 564 & 33 & 95 \\
\hline 4 & 3.597 & $2 \%$ & 34 & 1.258 & $1 \%$ & 4 & 683 & 34 & 239 \\
\hline 5 & 1.433 & $1 \%$ & 35 & 6.525 & $4 \%$ & 5 & 272 & 35 & 1.239 \\
\hline 6 & 1.215 & $1 \%$ & 36 & 647 & $0 \%$ & 6 & 231 & 36 & 123 \\
\hline 7 & 663 & $0 \%$ & 37 & 1.777 & $1 \%$ & 7 & 126 & 37 & 337 \\
\hline 8 & 793 & $0 \%$ & 38 & 9.183 & $5 \%$ & 8 & 151 & 38 & 1.744 \\
\hline 9 & 856 & $0 \%$ & 39 & 1.256 & $1 \%$ & 9 & 163 & 39 & 238 \\
\hline 10 & 10.040 & $6 \%$ & 40 & 3.908 & $2 \%$ & 10 & 1.907 & 40 & 742 \\
\hline 11 & 1.797 & $1 \%$ & 41 & 730 & $0 \%$ & 11 & 341 & 41 & 139 \\
\hline 12 & 2.279 & $1 \%$ & 42 & 750 & $0 \%$ & 12 & 433 & 42 & 142 \\
\hline 13 & 4.624 & $3 \%$ & 43 & 7.475 & $4 \%$ & 13 & 878 & 43 & 1.420 \\
\hline 14 & 2.523 & $1 \%$ & 44 & 1.057 & $1 \%$ & 14 & 479 & 44 & 201 \\
\hline 15 & 1.863 & $1 \%$ & 45 & 3.630 & $2 \%$ & 15 & 354 & 45 & 689 \\
\hline 16 & 6.952 & $4 \%$ & 46 & 1.147 & $1 \%$ & 16 & 1.320 & 46 & 218 \\
\hline 17 & 2.543 & $1 \%$ & 47 & 3.093 & $2 \%$ & 17 & 483 & 47 & 588 \\
\hline 18 & 11.333 & $7 \%$ & 48 & 3.829 & $2 \%$ & 18 & 2.153 & 48 & 727 \\
\hline 19 & 2.807 & $2 \%$ & 49 & 330 & $0 \%$ & 19 & 533 & 49 & 63 \\
\hline 20 & 7.809 & $4 \%$ & 50 & 2.984 & $2 \%$ & 20 & 1.483 & 50 & 567 \\
\hline 21 & 221 & $0 \%$ & 51 & 1.354 & $1 \%$ & 21 & 42 & 51 & 257 \\
\hline 22 & 5.891 & $3 \%$ & 52 & 4.842 & $3 \%$ & 22 & 1.119 & 52 & 920 \\
\hline 23 & 396 & $0 \%$ & 53 & 2.442 & $1 \%$ & 23 & 75 & 53 & 464 \\
\hline 24 & 330 & $0 \%$ & 54 & 4.900 & $3 \%$ & 24 & 63 & 54 & 931 \\
\hline 25 & 264 & $0 \%$ & 55 & 2.705 & $2 \%$ & 25 & 50 & 55 & 514 \\
\hline 26 & 2.741 & $2 \%$ & 56 & 359 & $0 \%$ & 26 & 521 & 56 & 68 \\
\hline 27 & 806 & $0 \%$ & 57 & 5.892 & $3 \%$ & 27 & 153 & 57 & 1.119 \\
\hline 28 & 5.383 & $3 \%$ & 58 & 1.976 & $1 \%$ & 28 & 1.023 & 58 & 375 \\
\hline 29 & 264 & $0 \%$ & 59 & 694 & $0 \%$ & 29 & 50 & 59 & 132 \\
\hline 30 & 1.797 & $1 \%$ & 60 & 1.757 & $1 \%$ & 30 & 341 & 60 & 334 \\
\hline \multicolumn{2}{|c|}{ TOTAL } & & & $\mathrm{R} \$ 174.206$ & & & TAL & & R\$ 33.088 \\
\hline
\end{tabular}

Fonte: Dados da Pesquisa (2009)

Como se pode notar na Tabela 5, é possível apurar a margem operacional bruta de cada cliente, levando-se em consideração o faturamento alcançado com cada cliente. Foram identificados os clientes mais rentáveis para a empresa: 18; 10; 38; 16; 20; 32; 35 e 43, e deveriam ser fidelizados e mantidos. Essa análise não é a tecnicamente mais correta de ser realizada, pois o ideal seria apurar, efetivamente, o custo para servir cada cliente, em cada rota e em cada filial, para apurar a margem operacional por cliente. Em função de carência de recursos humanos na empresa para auxiliar na obtenção dessas informações, e ainda não existir sistema de informação para gerar essas informações automaticamente, não foi possível realizar isso. 0 importante, na continuidade do trabalho, é analisar a lucratividade dos clientes nas diversas rotas, visando a verificar se a empresa está repassando seus custos para os clientes e obtendo os resultados objetivados.

A pesquisa-ação descrita neste estudo, sem dúvida, é uma análise que deve ter continuidade. As tabelas apresentadas para os gestores de cada uma das filiais, 
bem como para o Presidente da empresa e a controller da empresa, representam um momento de transição da empresa, que continua em expansão, e determinam um trabalho maior para buscar os as filiais, as rotas, os pontos e clientes mais lucrativos. Os gestores comentaram no final da pesquisa que pretendem dar continuidade às análises, principalmente na filial paranaense que apresenta resultado deficitário. $\mathrm{Na}$ sequência, são apresentadas as considerações finais deste trabalho.

\section{CONSIDERAÇÕES FINAIS}

Este trabalho enfatizou a importância das análises de lucratividade em nível multidimensional em empresas de serviços logísticos. Delineou-se este trabalho para um assunto que impactasse diretamente a gestão de uma empresa de serviços logísticos, haja vista que, se não fosse bem administrada, tenderia a levá-la para os caminhos da descontinuidade.

A opção pela discussão sobre a necessidade de análises de lucratividade em nível multidimensional; assim como a aplicação do conceito do custo para servir em empresa de serviços logísticos de pequeno porte como tema central deste estudo, deve-se ao entendimento de que, carecendo de habilidades gerenciais, o pequeno empresário acaba por não fazê-las, ou, quando as implanta, o faz, algumas vezes, de maneira incorreta.

Diante do mapeamento do processo logístico, identificou-se que os custos dos serviços prestados pela empresa analisada podem ser classificados em relação aos seguintes objetos de análise: empresa; filiais; veículos e rotas; pontos e clientes. Há custos que são diretamente apropriados às filiais, mas indiretos aos veículos e rotas, pontos e clientes; e há custos que são diretos aos veículos e rotas, mas indiretos aos pontos e clientes. Várias análises foram desenvolvidas para apurar os resultados nesses níveis multidimensionais, visando a aperfeiçoar a gestão dessa operação logística.

A pesquisa realizada trouxe uma melhoria significativa nos controles da empresa, pois, até então, não havia informações que pudessem orientar as melhores estratégias empresariais; a empresa trabalhava sem controles. Assim, como uma visão moderna para a gestão dos negócios, espera-se que resultará na mudança cultural dos comportamentos negociais, em especial da área comercial. Todavia, por mais importante que seja a cultura implantada e a inexistência de um sistema informatizado; ainda não permite a implantação segura de outras análises multidimensionais. Os proprietários, cientes dessas necessidades, pretendem implantar ações que permitam atender a esses quesitos, que requerem investimentos, visando a melhorar a gestão de sua operação logística.

Entende-se que o objetivo desta pesquisa foi atingido, uma vez que foi possível verificar, por meio de uma pesquisa-ação, como podem ser desenvolvidas análises de lucratividade em nível multidimensional em uma empresa de serviços logísticos de pequeno porte. A questão de pesquisa, também foi respondida, pois foram apurados os resultados por filial, ponto de distribuição, rota e cliente da empresa estudada.

Deve-se destacar que este trabalho tem seus resultados limitados à organização pesquisada. Não obstante, entende-se que a metodologia aqui empregada pode ser utilizada em outras empresas com vários objetos de custeio. Como recomendações para novos trabalhos, sugerem-se novas aplicações de análises de lucratividade em nível 
multidimensional em outras empresas de serviços logísticos ou de outros segmentos, para comprovar, reiterar ou refutar o que foi constatado nesta pesquisa.

\section{REFERÊNCIAS}

BRAITHWAITE, A.; SAMAKH, E. The cost-to-serve method. International Journal of Logistics Management, v.9, n.1.p.69-84, 1998.

CHRISTOPHER, M. Logística e Gerenciamento da cadeia de suprimentos. 2a. Ed. São Paulo: Thomson, 2007.

COKINS, G. Measuring customer value: how BPM supports better marketing decisions. Business Performance Management Magazine. v.4. n. 1. Cleveland: Fev, 2006.

FARIA, A. C.; COSTA, M. F.G. Gestão de custos logísticos. São Paulo: Atlas, 2005.

FIGUEIREDO, K. F. Rentabilidade de clientes e nível de Serviço. FLEURY, P. F.; WANKE, P.; FIGUEIREDO, K. F. IN: Logística Empresarial. Centro de Esstudos em Logística. São Paulo: Atlas, 2000.

FLEURY, P. F.; WANKE, P.; FIGUEIREDO, K. F. Logística empresarial: a perspectiva brasileira. Coleção COPPEAD de Administração. São Paulo: Atlas, 2000.

GATTORNA, John L.; WALTERS, D.W. Managing the supply chain: a strategic perspective. London: Macmillan Press, 1996.

GIL, A. C. Métodos e Técnicas de Pesquisa Social. 6ª . Ed. São Paulo: Atlas, 2008.

GUERREIRO, R.; BIO, S.R.; MERSCHMANN, E.V.V. Cost-to-serve measurement and customer profitability analysis. International Journal of Logistic Management. v. 19. n. 3, 2008.

HOWCROFT, J. Understanding profitability through cost-to-serve. Disponível em: $<w w w . a d v i s o r b a s e . c o . n z / C o s t t o S e r v e . p d f>$. Acesso em 21/05/2009.

IS Logística. Logística de Malotes. Disponível em: <http://www.islogistica.com.br/ islogistica/servicos_logistica_malotes.php> Acessado em 20/04/2009.

JEFFERY, M. M.; BUTLER, R.J.; MALONE, L.C. Determining a cost-effective customer service level. Supply Chain Management: an International Journal. v.13, n.3, 2008.

KAPLAN, R.S.; COOPER, R. Custo e desempenho: administre seus custos para ser mais competitiva. 2a.Ed. São Paulo: Futura, 2000.

; NARAYANAN, V.G. Measuring and managing customer profitability. Cost Management. Vol. 15, Iss. 5, p. 5-15. Boston:Set/Oct 2001.

KOTLER, P.; ARMSTRONG, G. Princípios de marketing. 9a. Ed. Rio de Janeiro. Prentice-Hall, 2003.

KRAFTA, L. Gestão da Informação como base da ação comercial de uma pequena empresa de TI. Dissertação (Mestrado em Administração). Programa de Pós-graduação em Administração da Universidade Federal do Rio Grande do Sul, 2007. 
KUMAR, V.; SHAH, D.; VENKATESAN, R. Managing retailer profitability - one customer at a time! Journal of Retailing. Vol. 82, Iss. 4. Greenwich, 2006.

MARTINS, G. de A. Estudo de caso: uma estratégia de pesquisa. São Paulo: Atlas, 2006.

MAXIMIANO, A. C. A. Administração para empreendedores: fundamentos da criação e da gestão de novos negócios. Şão Paulo: Pearson Prentice Hall, 2006.

MICHAELIS. Moderno dicionário da língua portuguesa. Disponível em:<http:// michaelis.uol.com.br> Acesso em 20.julho.2009.

MILONE, M. C. Análises de custos de servir e o impacto na relação entre indústria e varejo. Anais... In: VI Seminários de Administração - SemeAD, 2001.

MITTAL, V.; SARKEES, M.; MURSHED, F. The right way to unprofitable customers. Harvard Business Review. v. 86. n. 4. 2008.

NOREK, C.D.; POHLEN, L. Cost knowledge: a foundation for improving supply chain relationships. International Journal of Logistics Management, v.12, n.1, p.37-51, 2001.

REEVE, J.M. Logistics and marketing costs. In: REEVE, J.M. Handbook of Cost Accounting. Knoxville: Prentice Hall: University of Tennessee, 1998.

RICCIO, E. L.; HOLANDA, V. B. A utilização da pesquisa-ação para perceber e implementar sistemas de informações empresariais. Anais... IN: 13th Asian Pacific Conference On International Accounting Issues. Rio de Janeiro, 2001.

ROBLES JR., A.; ROBLES, L.T.; FARIA, A. C. Custos para servir: uma proposta de aplicação para uma indústria de tintas. Revista Universo Contábil. Blumenau, 2005.

ROSS, A.; JAYARAMAN, V.; ROBINSON, P. Optimizing 3PL service delivery using costto-serve approach. International Journal of Production Research. V. 45, n. 1. Jan, 2007.

STAPLETON, D; PATI, S; BEACH, E; JULMANICHOTI, P. Actvity based costing for logistics and marketing. Business Process Management Journal. V. 10. n. 5. 2004.

THIOLLENT, M. Metodologia da pesquisa-ação. 14. Ed. São Paulo: Cortez, 2005.

WANG, I. Li. Distribution of small packages in metropolitan area by motorcycle courier services. International Journal Integrated Supply Management, v. 4, no. 1, 2008. 


\section{ENDEREÇO DOS AUTORES:}

\section{Ana Cristina de Faria}

Universidade Municipal de São Caetano do Sul

Programa de Mestrado em Administração.

Rua Santo Antonio, 50 - Centro

São Caetano do Sul, SP - Brasil

09521-160

\section{Márcio Luiz Borinelli}

Universidade de São Paulo, Faculdade de Economia Administração e Contabilidade. Avenida Professor Luciano Gualberto, 908, Prédio 3, Sala 230

Cidade Universitária

São Paulo, SP - Brasil

05508-900

\section{Norival Mantovani}

Universidade Municipal de São Caetano do Sul

Programa de Mestrado em Administração.

Rua Santo Antonio, 50 - Centro

São Caetano do Sul, SP - Brasil

09521-160 